\title{
UNA PROPUESTA DIFERENTE PARA ERRADICAR LA POBREZA RURAL: TRANSFORMAR LOS AFECTADOS POR EL SUBDESARROLLO EN CONSTRUCTORES DEL DESARROLLO
}

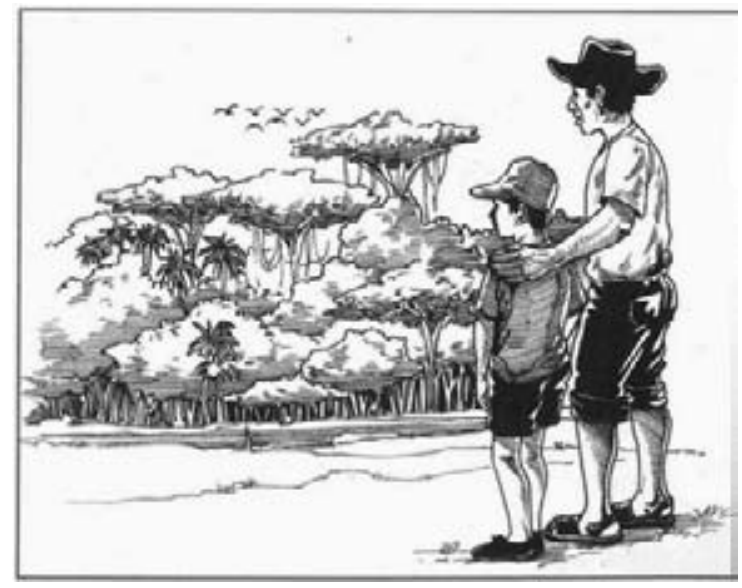

\section{Polan Lacki}

Rua Bispo Dom José, 2051, apto. 706. Telf: (55-41) 3243-2366. Cel: (55-41) 9602-1239. 8044-0080, Curitiva, Paraná, Brasil. E-mail: Polan.Lacki@uol.com.br / Polan.Lacki@onda.com.br http://www.polanlacki.com.br/http://www.polanlacki.com.br/ agroesp

$\mathrm{E}$ n América Latina los proyectos paternalista s de erradicación de la pobreza rural han sido y siguen siendo una sucesión de fracasos. Entre otras razones, porque parten del supuesto equivocado de que la principal causa de la pobreza de los agricultores, es la insuficiencia de sus recursos materiales y financieros; $y$ que consecuentemente el Estado debe proporcionarles más tierra, más animales, más maquinaria, más subsidios, más créditos, etc; y después que los proyectos fracasan---y casi siempre fracasan---concederles más refinanciamientos y finalmente condonar sus deudas.

El otro diagnóstico y la otra solución: Personalmente no estoy de acuerdo con ese diagnóstico ni con esas soluciones tan conservadoras, pues entiendo que el principal problema de los pobres rurales es el no saber hacer y no tanto el no tener recursos para hacerlo. La vivencia que he tenido con muchos de esos proyectos paternalistas en 19 países latinoamericanos me ha enseñado algo muy diferente de lo que está escrito en los textos académicos; entre otras cosas, lo siguiente:

---Un alto porcentaje de agricultores, aún siendo pobres, dispone de los recursos mínimos para empezar su desarrollo (algo de tierra propia o de terceros, algunos animales propios o en "medianeria” y muy especialmente una abundante mano de obra ). Al contrario de lo que suele afirmarse, la cantidad de recursos potencialmente productivos que esos agricultores disponen, más bien sobrepasa su capacidad de utilizarlos con eficiencia y en la plenitud de sus potencialidades. Confirman esta aseveración, la bajísima productividad de la mano de obra familiar y los igualmente bajísimos rendimientos que esos agricultores pobres obtienen de la tierra y de los animales que manejan.

---Lo que más hace falta a los pobres rurales es el saber y el saber hacer ( conocimientos, habilidades, aptitudes, actitudes y valores ) para que tengan la capacidad de incrementar la productividad y el rendimiento de la mano de obra familiar, de la tierra y de los animales que ya disponen. Reiterados trabajos de investigación y extensión rural han demostrado que gran parte de dichos incrementos puede ser obtenida, apenas con mejores conocimientos; es decir, sin necesidad de proporcionarles más recursos materiales y financieros. A propósito sugiero consultar el texto "Desarrollo agropecuario: de la dependencia al protagonismo del agricultor” disponible en la nueva Página http://www.polanlacki.com.br/agroesp

¿Qué es lo que más necesitan los pobres: créditos generosos o conocimientos útiles? Todolo anteriorsignifica que los proyectos paternalistas están sobreestimando la falta del financiamiento ( que los gobiernos no disponen en cantidad suficiente para ofrecer a todas las familias rurales ) y subestimando la falta del conocimiento ( que está disponible pero, en gran parte, permanece ocioso en los organismos de investigación ). Asimismo significa que, en países cuyos gobiernos están tan “desfinanciados” 
como los nuestros, estamos cometiendo el contrasentido de ofrecer a los agricultores recursos adicionales en vez de enseñarles a utilizar más racionalmente los que ellos ya poseen. $\mathrm{Y}$ es debido a estas irracionalidades que estamos llevando los pobres rurales al banco antes de ofrecerles una educación rural de buena calidad. Como no poseen el saber y el saber hacer, los pobres rurales en vez de actuar como agentes de su propio desarrollo, involuntariamente, ac túan como causadores del subdesarrollo. Este es el problema de fondo y consecuentemente una educación emancipadora deberá ser el punto de partida para una gran solución.

Una propuesta de sentido común: transformar el factor potencial en un factor real de desarrollo: LoS proyectos de desarrollo rural recién tendrán éxito después que proporcionen a los afectados por el subdesarrollo, en primerísimo lugar, el saber y el saber hacer para que puedan actuar como constructores del desarrollo ( personal, familiar, comunitario, municipal, etc ). En el medio rural el recurso más abundante, y potencialmente más eficaz para generar riqueza y prosperidad, son las propias familias rurales. Sin embargo, de poco sirve disponer de familias llenas de potencialidades latentes. Es necesario que los proyectos tengan el objetivo y la capacidad ( reitero, intencionalmente, el objetivo y la capacidad) de transformar ese abundante factor potencial en un eficiente factor real de desarrollo. Entonces la solución más apropiada consiste en ofrecerles una educación útil, funcional e instrumental que les enseñe a producir con mayor eficiencia y rentabilidad, aunque no accedan a recursos materiales y financieros adicionales a los que ellos ya poseen. Proporcionándoles una educación orientada al auto desarrollo, estos pobres quienes actualmente hacen parte del problema, pasarán a hacer parte de la solución. Con ello tendremos una menor cantidad de familias rurales reivindicando infructuosamente recursos al Ministerio de Hacienda y una mayor cantidad de ellas generando dichos recursos en sus propias fincas, al practicar una agricultura más eficiente, más productiva y más rentable.

"Funcionarios públicos" no estatales reemplazando a funcionarios públicos estatales: Después que los gobiernos adopten una estrategia educativo-emancipadora, los propios pobres rurales podrán actuar como si fuesen "funcionarios públicos" no estatales, reemplazando en gran parte a los funcionarios públicos convencionales. Debidamente capacitados estos pobres estarán aptos a corregir sus propias ineficiencias y a solucionar, ellos mismos, muchos de los problemas que ocurren en sus fincas, en sus hogares, en sus comunidades y en los mercados rurales. A su vez los gobiernos ahorrarán sus escasos recursos porque esos "nuevos funcionarios públicos" no exigirán sueldos, viáticos, vehículos, aguinaldos, vacaciones, ni jubilaciones...y por último, no harán huelgas, no reivindicarán "derechos adquiridos" ni practicarán los tan odiosos y cada vez más frecuentes actos de corrupción. Porque serán los propios agricultores, luego de recibir una educación orientada al protagonismo y al "emprendedorismo", quienes harán aquello que los gobiernos inoperantes, perdularios e ineficientes, durante años y décadas, no han sido capaces de hacer por ellos.

Ya no hay tiempo para utopías ni ilusiones; las soluciones paternalistas están agotadas. Debido a la crónica insuficiencia de recursos públicos, idéntica estrategia de educar para emancipar, tendrá que ser adoptada en relación a los habitantes urbanos. El creciente desequilibrio entre lo que reivindican los ciudadanos y la decreciente capacidad de los gobiernos en satisfacer sus peticiones está exigiendo que nuestro sistema de educación tenga como un importante objetivo el de formar ciudadanos que reemplacen, hasta donde sea posible, la dependencia por la emancipación. Esta tendencia, en la cual los propios afectados por los problemas están solucionándolos, ya está manifestándose en el sector laboral ( auto empleo ), en la previdencia o seguridad social, en los servicios de salud, en la protección policial, etc.

Los gobiernos pobres no pueden actuar como si fuesen ricos: El desequilibrio mencionado en el párrafo anterior no es privilegio de los empobrecidos gobiernos de los países latinoamericanos pues ya está siendo reconocido hasta en los países más ricos del mundo, cuyos gobiernos están siendo obligados a reducir, drásticamente, las ayudas paternalistas que durante mucho tiempo concedieron a sus ciudadanos; porque sus presupuestos, por abultados que sean, sencillamente ya no soportan financiar ayudas tan generosas. Si los países ricos están haciéndolo, con muchísima más razón tendrán que hacerlo los gobiernos de los empobrecidos y endeudados países latinoamericanos. Nuestros gobiernos, inexorablemente, tendrán que priorizar el "empoderamiento" de los ciudadanos y convocarlos para que ellos mismos---en forma individual y grupal---solucionen algunos de sus problemas y adicionalmente generen ingresos adicionales con los cuales puedan pagar a las empresas privadas para que éstas les proporcionen los servicios que los gobiernos, definitivamente, no están en condiciones de ofrecerles. 